\title{
"PAI DE SANTO DOUTOR": ESCOLARIDADE, GÊNERO E COR NOS TERREIROS BAIANOS
}

Jocélio Teles dos Santos ${ }^{*}$

Luiz Chateaubriand C. dos Santos ${ }^{* *}$

"Agora, tem até pai de santo doutor". O comentário em terreiros baianos traduz a percepção do povo de santo sobre a existência de lideranças com escolaridade de nível superior. Claro está que é um fato das últimas três décadas num universo secularmente observado como de maioria negra e com pouca instrução, indicando os obstáculos enfrentados por essa população no acesso à escolaridade. Neste artigo buscamos traçar o perfil dessas lideranças, tendo como fonte de dados o mapeamento dos terreiros realizado em Salvador no período 2006-2008.

A presença de indivíduos oriundos das classes médias e também das elites em terreiros baianos já foi apontada na literatura, nos estudos afro-brasileiros e na imprensa há mais de cem anos, e mesmo que os registros indiquem somente a posição social, se tratava de indivíduos brancos. Eram clientes, adeptos ou mesmo pais ou mães de santo.

Em pleno século XIX, uma boa medida para perceber esta presença está nas matérias da imprensa. A reação virulenta crescia quando se verificava que entre os consulentes se encontravam, além da popula-

Professor da Universidade Federal da Bahia. E-mail: jocelio@ufba.br

** Sociólogo, doutorando no Programa de Pós-Graduação em Estudos Étnicos e Africanos da Universidade Federal da Bahia. E-mail: luizchateau@uol.com.br 
ção negra e de seus descendentes, senhoras casadas e comerciantes. Era o que acontecia em um candomblé, situado no Beco dos Barris, "nos fundos da roça da viúva Serva", e qualificado, em 2 de setembro de 1868, como "maldito". ${ }^{1}$

A qualificação de maldito que esse candomblé recebera era bastante sintomática da sua representatividade perante diversos grupos sociais. O que vemos são senhoras, senhores e escravos procurando o terreiro pelos mais variados motivos:

fatalmente atraídas, pela credulidade senhoras casadas, que vão procurar específicos, que façam com seus maridos não se esqueçam dos deveres conjugais; escravos que vão pedir ingredientes para abrandar o ânimo de seus senhores; mulheres, que vão buscar os meios de fazer felicidade e até negociante para terem bom andamento em seus negócios!. ${ }^{2}$

Brancos católicos em candomblés baianos constituíam um problema de ordem religiosa e moral. Religiosa no sentido de que os católicos ao adentrarem espaços "bárbaros" infringiam credos cristãos. Além disso, a procura por práticas mágico-religiosas de origem africana tinha um sentido moral, visto que um número considerável de pessoas era constituído por mulheres solteiras e casadas na tentativa de resolver os seus problemas afetivos.

É o que podemos encontrar na voz da personagem Paulo Boto, do romance $O$ Feiticeiro, quando questionava

Quem o mais culpado - o negro que faz pela vida, explorando a crendice do branco, ou o branco civilizado e católico que procura o africano e se deixa explorar? Não me consta que eles obriguem mulher casada, viúva ou solteira a ir às suas capelas dar dinheiro em troca de vaticínios ou remédios. Elas vão por sua livre vontade, porque crêem e não consideram o passo nem ridículo nem vergonhoso. ${ }^{3}$

As senhoras e senhoritas, portanto, não tinham pudor algum em buscar os conselhos de pais e mães de santo. Para elas não constituía

O Alabama, 2 de setembro de 1868

O Alabama, 2 de setembro de 1868 .

Xavier Marques, O feiticeiro, São Paulo: Edições GRD/Instituto Nacional do Livro, 1975, p. 19. 
nenhum paradoxo ter princípios cristãos, frequentar missas, participar de novenas e, ao mesmo tempo, buscar nos terreiros as respostas para os seus fatídicos desejos e problemas.

A procura de senhoras e senhoritas brancas pelos terreiros de candomblé demonstra que as imagens sobre as práticas e rituais de origem africana estavam espraiadas pela população da cidade. Elas entrecruzavam as classes e grupos sociais no Brasil oitocentista. É o que demonstra Nina Rodrigues, ${ }^{4}$ no final do século, quando dizia:

Não se creia que só negros e ignorantes freqüentem os terreiros e candomblés em busca de tratamento aos seus males. Todos nós médicos sabemos a freqüência com que os doentes, à revelia do assistente, ou despedindo-o sob o pretexto mais fútil, vão se entregar aos cuidados dos feiticeiros, vão se tratar com folhas do mato, no eufemismo da frase consagrada.

A expressão "se tratar com folhas do mato", grifada por Nina Rodrigues, tem o sentido do uso de uma farmacopeia de origem africana, assim como expressa, metaforicamente, o tipo de tratamento que era o contraponto ao da medicina oficial.

E o que se observava nos brancos detentores de funções hierárquicas nos terreiros? Como escreveu Artur Ramos, nos anos trinta do século vinte, no cargo hierárquico de ogã havia a presença de indivíduos brancos oriundos das elites exercendo uma função importante nos terreiros baianos. E assim os designava: "o ogã é quase sempre um branco, senhor, a quem os negros respeitam, enxergando nele um protetor do terreiro". ${ }^{5} \mathrm{O}$ médico cientista sabia muito bem o que afirmava; afinal, ele tornara-se ogã do terreiro do Gantois, para "fins de pesquisa científica", na mesma época que Hosannah de Oliveira, seu amigo e professor da Faculdade de Medicina da Bahia.

O terreiro do Gantois que, segundo Donald Pierson, tornara-se "a sede das pesquisas de Nina e, mais, das de Arthur Ramos", 6 revela-nos

\footnotetext{
4 Nina Rodrigues, O animismo fetichista dos negros baianos, Rio de Janeiro: Civilização Brasileira, 1935, p. 97.

5 Artur Ramos, O negro brasileiro, Recife: Fundação Joaquim Nabuco/Editora Massangana, 1988, p. 51 e passim; Sobre os ogãs, ver Júlio Braga, A cadeira de ogã e outros ensaios, Rio de Janeiro: Pallas, 1999.

6 Donald Pierson, Brancos e pretos na Bahia, São Paulo: Companhia Editora Nacional, 1971, p. 306.
} 
certa "tradição científica", pois Nina Rodrigues havia sido elevado ao posto de ogã no mesmo terreiro, e Estácio de Lima, também médico e professor da Faculdade de Medicina e de Direito, era ogã da Oxum de Mãe Menininha, no período, 1938-1939, em que a antropóloga norteamericana Ruth Landes realizou pesquisas em Salvador. ${ }^{7}$ Além de cientistas, podem ser observados, nas primeiras décadas do século, entre os ogãs do Gantois, dois generais do exército. ${ }^{8}$

Desde o século XIX, os ogãs ocupavam um papel fundamental nos candomblés diante da sociedade escravista. Como observara o romancista Xavier Marques, eram "os protetores influentes e beneméritos" dos terreiros. ${ }^{9}$ Nina Rodrigues, um contemporâneo do romancista, dizia que os ogãs eram

os responsáveis e protetores do candomblé. A perseguição de que eram alvo os candomblés e a má fama em que são tidos os feiticeiros tornavam uma necessidade a procura de protetores fortes e poderosos que garantissem a tolerância da policia. A estes protetores que podem ser iniciados ou não, mas que ou acreditam na feitiçaria, ou têm um interesse qualquer nos candomblés, dão eles em recompensa o título e as honras de ogãs. Os ogãs têm obrigações limitadas e direitos muito amplos. Além da proteção dispensada devem fazer ao seu santo presentes de animais para as festas e sacrifícios. Têm direitos a cumprimentos especiais dos filhos de santo, a serem ouvidos nas deliberações do terreiro, a saírem todos os santos e o terreiro em seu favor, no caso que estejam ameaçados de alguma ofensa ou desgraça. ${ }^{10}$

Uma relação de troca entre sujeitos hierarquicamente desiguais.

Sendo o ogã uma função hierárquica masculina, a sua subordinação estava relacionada ao pai ou mãe de santo, fossem eles negros, mestiços e até brancos. E brancos liderando candomblés não é um fenô-

\footnotetext{
Ruth Landes, A cidade das mulheres, Rio de Janeiro: Civilização Brasileira, 1967, p. 83.

8 João da S. Campos, "Costumes e crenças dos afro-baianos", Revista de Sociologia, v. XI, n. 4 (1949), p. 442. Para uma análise mais desenvolvida sobre o terreiro do Gantois e a ascensão de Menininha do Gantois, ver Jocélio T. dos Santos, "Menininha do Gantois: a sacralização do poder", in Vagner G. da Silva (org.), Caminhos da alma: memória afro-brasileira (São Paulo: Summus, 2002), pp.133-52.

.9 Marques, $O$ feiticeiro, p. 30 .

io Rodrigues, $O$ animismo fetichista dos negros baianos, p. 70.
} 
meno recente. João Reis ${ }^{11}$ indica que entre os anos cinquenta e setenta do século XIX havia duas lideranças brancas - Maria do Couto e Domingos Miguel. Seus terreiros estavam localizados, respectivamente, no Saboeiro (longe da cidade) e em Água de Meninos (área mais próxima do centro). Possuíam a mesma cor, mas tinham um diferencial: a nacionalidade. Domingos não era baiano, muito menos brasileiro. Era português. Os dois foram alvos da perseguição policial, mas Domingos, um estrangeiro, não foi deportado como os africanos considerados feiticeiros, provavelmente, o seriam. Infelizmente, não temos mais informações sobre esses terreiros para saber se eles adentraram pelo século XX ou desapareceram.

\section{Em cena os séculos XX e XXI}

Não dispomos de informações sobre lideranças brancas no início do século XX. Mas, podemos verificar pelo mapeamento realizado em 20062008 a existência de terreiros liderados por brancos, alguns deles seus fundadores.

$\mathrm{O}$ resultado da pesquisa mostrou que a maioria das lideranças dos terreiros declarou-se de cor preta $(60,3 \%)$; se acrescentarmos o percentual de pardos $(31,6 \%)$, o total de lideranças negras nos terreiros soteropolitanos corresponde a 91,6\%. O percentual de brancos é de 4,8\%, o que corresponde a 53 terreiros, em um universo de $1.104^{12}$ (Tabela 1).

Em que momento estes terreiros liderados atualmente por brancos foram constituídos? Os dados da pesquisa revelam que dois dos terreiros liderados por brancos foram fundados entre os anos vinte $\mathrm{e}$ quarenta do século XX (Tabela 2).

O primeiro, em 1922, é dirigido por uma mãe de santo há vinte e

\footnotetext{
11 João J. Reis, Domingos Sodré, um sacerdote africano: escravidão, liberdade e candomblé na Bahia do século XIX, São Paulo: Companhia das Letras, 2008.

12 Os percentuais divergem dos que podem ser calculados com os dados da Tabela 1 devido ao fato do total de terreiros da tabela (1.104) ser menor que o encontrado pela pesquisa (1.162) Isso ocorre em razão da recusa de alguns informantes em atribuir raça ou cor a liderança religiosa ou informar o ano de fundação do terreiro. Sobre o mapeamento, ver Jocélio T. dos Santos, Mapeamento dos terreiros de Salvador, Salvador: Ceao, 2008. Também disponível em <www.terreiros.ceao.ufba.br>.
} 
Tabela 1

Cor ou raça das lideranças religiosas segundo 0 ano de fundação dos terreiros

Salvador, 2006-2008

\begin{tabular}{|c|c|c|c|c|c|c|}
\hline \multirow{2}{*}{$\begin{array}{l}\text { Ano de } \\
\text { fundação }\end{array}$} & \multicolumn{5}{|c|}{ Cor ou raça } & \multirow[b]{2}{*}{ Total } \\
\hline & Preta & Parda & Branca & Amar. & Indíg. & \\
\hline \multirow[t]{2}{*}{ Até 1899} & 5 & 3 & & & & 8 \\
\hline & 0,8 & 0,9 & & & & 0,7 \\
\hline \multirow[t]{2}{*}{1900 a 1909} & 3 & 2 & & & & 5 \\
\hline & 0,5 & 0,6 & & & & 0,5 \\
\hline \multirow[t]{2}{*}{1910 a 1919} & 4 & & & & & 4 \\
\hline & 0,6 & & & & & 0,4 \\
\hline \multirow[t]{2}{*}{1920 a 1929} & 3 & 3 & 1 & & & 7 \\
\hline & 0,5 & 0,9 & 2 & & & 0,6 \\
\hline \multirow[t]{2}{*}{1930 a 1939} & 11 & 5 & & & & 16 \\
\hline & 1,7 & 1,4 & & & & 1,4 \\
\hline \multirow[t]{2}{*}{1940 a 1949} & 23 & 8 & 1 & & 2 & 34 \\
\hline & 3,5 & 2,3 & 1,9 & & 6,5 & 3,1 \\
\hline \multirow[t]{2}{*}{1950 a 1959} & 38 & 13 & 4 & & 2 & 57 \\
\hline & 5,7 & 3,7 & 7,5 & & 6,5 & 5,2 \\
\hline \multirow[t]{2}{*}{1960 a 1969} & 70 & 40 & 5 & 1 & 3 & 119 \\
\hline & 10,6 & 11,5 & 9,4 & 11,1 & 9,7 & 10,8 \\
\hline \multirow[t]{2}{*}{1970 a 1979} & 114 & 59 & 7 & 2 & 7 & 189 \\
\hline & 17,2 & 16,9 & 13,2 & 22,2 & 22,6 & 17,1 \\
\hline \multirow[t]{2}{*}{1980 a 1989} & 139 & 62 & 14 & 2 & 5 & 222 \\
\hline & 21,0 & 17,8 & 26,4 & 22,2 & 16,1 & 20,1 \\
\hline \multirow[t]{2}{*}{1990 a 1999} & 152 & 97 & 12 & 3 & 10 & 274 \\
\hline & 23,0 & 27,8 & 22,6 & 33,3 & 32,3 & 24,8 \\
\hline \multirow[t]{2}{*}{2000 a 2006} & 100 & 57 & 9 & 1 & 2 & 169 \\
\hline & 15,1 & 16,3 & 17,0 & 11,1 & 6,5 & 15,3 \\
\hline \multirow[t]{2}{*}{ Total } & 662 & 349 & 53 & 9 & 31 & 1104 \\
\hline & $100 \%$ & $100 \%$ & $100 \%$ & $100 \%$ & $100 \%$ & $100 \%$ \\
\hline
\end{tabular}

Fonte: Mapeamento dos terreiros de Salvador. Ceao/Semur/ Sehab, 2008.

dois anos, pertence à nação ijexá e está localizado na Av. Vasco da Gama. O segundo, fundado em 1946, é da nação angola, liderado também por uma mulher há 35 anos e localizado no bairro do Cabula. Podem ser consideradas as lideranças brancas em terreiros existentes há mais de sessenta anos.

A partir dos anos cinquenta há uma tendência de crescimento do número de terreiros atualmente sob a liderança de branco(a)s, sendo 
Tabela 2

Terreiros liderados por brancos, por data de fundação Salvador, 2006-2008

\begin{tabular}{lccc}
\hline Data de fundação & $\begin{array}{c}\text { Número de } \\
\text { terreiros }\end{array}$ & $\begin{array}{c}\text { Distribuição } \\
\text { relativa (\%) }\end{array}$ & $\begin{array}{c}\text { Distribuição relativa } \\
\text { acumulada (\%) }\end{array}$ \\
\hline 1922 & 1 & 1,9 & 1,9 \\
1946 & 1 & 1,9 & 3,8 \\
1950 a 1959 & 4 & 7,5 & 11,3 \\
1960 a 1969 & 5 & 9,4 & 20,8 \\
1970 a 1979 & 7 & 13,2 & 34,0 \\
1980 a 1989 & 14 & 26,4 & 60,4 \\
1990 a 1999 & 12 & 22,6 & 83,0 \\
2000 a 2009 & 9 & 17,0 & 100 \\
Total & 53 & 100 & \\
\hline
\end{tabular}

Fonte: Mapeamento dos terreiros de Salvador. Ceao/Semur/ Sehab, 2008.

quatro terreiros nesta década. Um é de umbanda, localizado no bairro de Castelo Branco, e é liderado pela sua fundadora há 58 anos. Criado em 1950, é a mais antiga casa de umbanda que encontramos em Salvador, e no momento da pesquisa a mãe de santo estava com 85 anos. É, portanto, a liderança/fundadora de cor branca mais idosa do universo religioso afro-baiano.

Os outros três terreiros possuem as seguintes características: um é da nação keto, fundado em 1951, localizado no bairro do Uruguai, sendo ainda liderado pela sua fundadora que estava com 79 anos. O segundo, registrado em 1956, também pertence à umbanda e está localizado no bairro de Pernambués; a atual liderança não foi a sua fundadora, mas ela está à frente do terreiro "há mais de quarenta anos". O quarto terreiro desse período foi criado em 1958, é da nação nagô vodum, está localizado no bairro de Itapuã, e o seu fundador e ainda líder estava com 67 anos.

A pesquisa assinalou cinco terreiros nos anos sessenta e, na década seguinte, sete. Os dos anos sessenta estão localizados nos seguintes bairros e respectivas nações: Alto de Coutos (ketu), Dom Avelar (umbanda), Arenoso (ketu), Paripe (angola) e Cidade Nova (ketu).

Nessa mesma direção encontramos os sete terreiros liderados por brancos, fundados nos anos setenta e localizados nos bairros de Roma 
(angola), Praia Grande (ijexá), Itapuã (ketu), Fazenda Grande IV(ketu), Castelo Branco (ketu), Periperi (angola) e Caminho de Areia (amburaxó).

Nos anos oitenta foram fundados 14 terreiros e atualmente são liderados por indivíduos brancos. São 2 da nação angola, localizados nos bairros de Paripe e no Trobogy; 1 jeje em Pernambués; 1 ketu-jeje em São Tomé de Paripe; 2 da nação ketu-angola em Cajazeiras X e São Cristovão; 1 terreiro ketu em cada um dos bairros que se seguem: Castelo Branco, Fazenda Coutos, Pau da Lima, Paripe, Ribeira, Periperi; e, dessa mesma nação, 2 terreiros no bairro do Uruguai.

Nos anos noventa houve um pequeno decréscimo para 12 terreiros. Cinco deles são da nação angola e estão localizados nos bairros da Calçada, Curuzu, Fazenda Grande do Retiro, Paripe, São Caetano, Trobogy; 1 jeje na Massaranduba; 5 ketu situados em Paripe, Alto de Coutos, Plataforma, São Caetano e Valéria; e 1 ketu-angola também em Valéria.

Já nos seis primeiros anos do século XXI temos a seguinte distribuição dos nove terreiros fundados nesse período e liderados por brancos: 2 da nação angola, localizados em Paripe e São Tomé de Paripe; 3 jejes em Sussuarana, Pau da Lima e Fazenda Grande IV; 4 da nação keto na Calçada, Alto da Terezinha, Itapuã e Periperi.

A participação da nação ketu no conjunto desses terreiros corresponde a $47,2 \%$, vindo a seguir a nação angola com $22,6 \%$, jeje $(9,4 \%)$, ketu/angola e a umbanda, respectivamente com a mesma taxa de participação: 5,7\%. É interessante observar que a presença de lideranças brancas entre os vinte terreiros de umbanda encontrados é pequena. Correspondem somente a $15 \%$ e estão em três terreiros criados até o início dos anos sessenta. Isto demonstra que no universo umbandista baiano há uma sobre-representação de lideranças que podemos apontar como negras (pretas + pardas) ao longo dos últimos quarenta anos. As lideranças pretas (sete) têm mais que o dobro de participação que os brancos, e os pardos são três vezes mais: nove. E se observarmos que no universo pesquisado encontram-se quatro terreiros que se declararam da nação angola/umbanda, ou seja, de tradição bantu e que cultuam entidades de origem umbandista, verifica-se que há uma participação exclusivamente de lideranças pretas. 


\section{A escolaridade, a cor e o gênero}

O Mapeamento dos terreiros de Salvador revelou que o nível fundamental incompleto é a escolaridade de $46,9 \%$ das lideranças religiosas. Esse é o grau de instrução mais comum. O maior percentual dos que têm algum nível de escolaridade concluída encontra-se no ensino médio $-25,6 \%$. Encontramos 54 lideranças religiosas com o curso superior completo e 26 que ingressaram no ensino superior, embora não tivessem concluído o curso até o momento da entrevista. $\mathrm{O}$ que dá um percentual de $8,0 \%$ de pais e mães de santo ( 80 pessoas) que ingressaram no ensino superior.

Entre as lideranças com curso superior incompleto, mais de dois quintos $(42,3 \%)$ frequentavam a escola no momento da entrevista. Esse percentual de presença nas escolas é o mais elevado entre todos os níveis de escolaridade. Três lideranças $(5,6 \%)$ com curso superior completo declararam que frequentavam algum curso de pós-graduação.

A presença relativa de brancos é mais elevada entre as lideranças religiosas com o curso superior completo $(13,0 \%)$. A parcela de pretos é menor entre os que ingressaram nos cursos superiores $(53,7 \%$ dos que concluíram o curso superior e $50,0 \%$ dos que tinham grau superior incompleto) que a existente entre os líderes religiosos $(58,2 \%)$. O percentual de pardos entre os que frequentaram o curso superior é relativamente próximo ao do universo de líderes religiosos: $29,6 \%$ e $30,8 \%$, respectivamente. Com isso, a parcela de negros (pardos + pretos) entre as lideranças do candomblé é de cerca de nove pessoas em cada grupo de dez (88,9\%), porém, ela diminui na medida em que aumenta a escolaridade: $89,5 \%$ entre os que têm até o curso médio incompleto; $89,0 \%$ entre os de nível médio; $84,6 \%$ no de superior incompleto e $83,3 \%$ no superior completo.

Contrariamente ao que acontece no conjunto das lideranças religiosas, que apresenta esmagadora maioria feminina de quase dois terços do total $(63,7 \%)$, os homens prevalecem entre as que possuem o curso superior completo $(51,9 \%)$. A presença masculina aumenta na medida em que cresce o grau de instrução. A igualdade entre os gêneros $(50 \%$ para cada um) ocorre entre as que possuem o curso superior incompleto.

Além disso, a pesquisa mostrou que entre os que possuem o curso superior completo $(4,7 \%)$ ou incompleto $(2,3 \%)$ não havia diferença sig- 
Tabela 3

Escolaridade da liderança religiosa, segundo 0 ano de fundação do terreiro Salvador, 2006-2008

\begin{tabular}{lccc}
\hline & \multicolumn{2}{c}{ Escolaridade } & \\
\cline { 2 - 3 } Ano de fundação & $\begin{array}{c}\text { Até o curso médio } \\
\text { completo }\end{array}$ & $\begin{array}{c}\text { Superior incomp. e } \\
\text { completo }\end{array}$ & Total \\
\hline Até 1976 & 356 & 24 & 380 \\
Após 1976 & 34,3 & 30,0 & 34,0 \\
Total & 683 & 56 & 739 \\
& 1039 & 70,0 & 1119 \\
\hline
\end{tabular}

Fonte: Mapeamento dos terreiros de Salvador. Ceao/Semur/ Sehab, 2008.

nificativa no número de homens e mulheres. Não foi sempre assim. Se fizermos um recorte utilizando o ano de liberalização dos candomblés do controle da Delegacia de Jogos e Costumes (1976) como marco inicial e o agrupamento dos que possuíam o curso superior incompleto ou completo, encontraremos diferenças acentuadas entre o grupo masculino e feminino: são 33 homens nessa condição e apenas 23 mulheres.

O crescimento do número de terreiros, a partir da segunda metade dos anos 1970, revelava os significados da liberdade religiosa para o povo de santo, pois somente em 1976 foram criados 46 terreiros, o que representou uma média acima de três terreiros a cada mês. Nos anos seguintes, o número anual esteve acima de dez, e em um único ano (1986) houve o maior número de terreiros fundados na história da religiosidade afro-baiana, 57, uma média de quase cinco a cada mês.

Entre os dois momentos selecionados, "até 1976" e "após 1976", observamos que o percentual daqueles que ingressaram no ensino superior, cursando-o integralmente, ou mesmo abandonando-o, em algum semestre, cresceu. Entre os terreiros fundados até 1976, 6,3\% eram liderados por pessoas com curso superior completo ou incompleto e, entre os criados após 1976, 7,6\% possuíam a mesma escolaridade. Dito de outra forma: apenas $30,0 \%$ dos terreiros liderados pelos "doutores", foram fundados antes de 1976 (Tabela 3). 
Tabela 4

Cor ou raça das lideranças religiosas com o curso superior incompleto ou completo, segundo o ano de fundação dos terreiros

Salvador, 2006-2008

\begin{tabular}{|c|c|c|c|c|c|c|c|}
\hline \multirow[t]{2}{*}{ Anos } & \multicolumn{6}{|c|}{ Cor ou raça } & \multirow[b]{2}{*}{ Total } \\
\hline & Preta & Parda & Branca & Amar. & Indíg. & $\begin{array}{c}\text { Não } \\
\text { informou }\end{array}$ & \\
\hline \multirow{2}{*}{ Até 1899} & & 1 & & & & & 1 \\
\hline & & 4,0 & & & & & 1,3 \\
\hline \multirow{2}{*}{1900 a 1909} & 1 & & & & & & 1 \\
\hline & 2,4 & & & & & & 1,3 \\
\hline \multirow{2}{*}{1910 a 1919} & 1 & & & & & & 1 \\
\hline & 2,4 & & & & & & 1,3 \\
\hline \multirow{2}{*}{1920 a 1929} & 1 & & & & & & 1 \\
\hline & 2,4 & & & & & & 1,3 \\
\hline \multirow{2}{*}{1930 a 1939} & & 2 & & & & & 2 \\
\hline & & 8,0 & & & & & 2,5 \\
\hline \multirow{2}{*}{1940 a 1949} & 1 & & & & & & 1 \\
\hline & 2,4 & & & & & & 1,3 \\
\hline \multirow{2}{*}{1950 a 1959} & 2 & & 1 & & & & 3 \\
\hline & 4,8 & & 11,1 & & & & 3,8 \\
\hline \multirow{2}{*}{1960 a 1969} & 6 & 2 & 1 & & 1 & & 10 \\
\hline & 14,3 & 8,0 & 11,1 & & 50,0 & & 12,5 \\
\hline \multirow{2}{*}{1970 a 1979} & 3 & 3 & & & & & 6 \\
\hline & 7,1 & 12,0 & & & & & 7,5 \\
\hline \multirow{2}{*}{1980 a 1989} & 11 & 2 & 3 & & & 1 & 17 \\
\hline & 26,2 & 8,0 & 33,3 & & & 100,0 & 21,3 \\
\hline \multirow{2}{*}{1990 a 1999} & 10 & 11 & 3 & 1 & 1 & & 26 \\
\hline & 23,8 & 44,0 & 33,3 & 100,0 & 50,0 & & 32,5 \\
\hline \multirow{2}{*}{2000 a 2006} & 6 & 4 & 1 & & & & 11 \\
\hline & 14,3 & 16,0 & 11,1 & & & & 13,8 \\
\hline \multirow[b]{2}{*}{ Total } & 42 & 25 & 9 & 1 & 2 & 1 & 80 \\
\hline & $100 \%$ & $100 \%$ & $100 \%$ & $100 \%$ & $100 \%$ & $100 \%$ & $100 \%$ \\
\hline
\end{tabular}

Fonte: Mapeamento dos terreiros de Salvador. Ceao/Semur/ Sehab, 2008.

Muito mais que o dobro. E a participação das lideranças brancas é deveras significativa. $\mathrm{O}$ total de brancos que esse estrato indica é de $11,3 \%$, comparando-os com os outros grupos (52,5\% de pretos, $31,3 \%$ de pardos, $1,3 \%$ de amarelos e 2,5\% de indígenas). Entretanto, na totalidade de indivíduos de cada grupo de raça ou cor, as lideranças brancas com instrução superior têm a maior participação, já que são 9 de um total de 53 terreiros, o que corresponde a 17,0\%, enquanto as lideranças 
pretas e pardas com curso superior incompleto ou completo são, respectivamente, $6,4 \%$ e $7,1 \%$ (Tabela 4 ).

Quando observado o gênero, a diferença é pequena. São 41 terreiros liderados por homens e 39 por mulheres. Mas, se utilizarmos o ano de fundação, verifica-se uma distância entre os dois grupos: após 1976, houve mais que o dobro de terreiros criados por esse estrato de escolaridade. Eram 24 aos quais se acrescentaram 56. Até o ano de 1976, o percentual de mulheres era o dobro do masculino; após 1976, ocorreu um aumento da taxa de participação masculina de 33,3\% para 58,9\%. O crescimento das mulheres foi pequeno, passando de 16 em 1976 para 23 terreiros no período posterior. E a taxa de participação feminina caiu de $66,7 \%$ para $41,1 \%$ após 1976 (Tabela 5). O que sugere uma associação entre liberdade religiosa e a assunção de lideranças masculinas com acesso ao ensino superior.

\section{Tabela 5}

Sexo das lideranças religiosas com o curso superior completo ou incompleto, segundo 0 ano de fundação do terreiro Salvador, 2006-2008

\begin{tabular}{|c|c|c|c|}
\hline \multirow{2}{*}{ Ano de fundação } & \multicolumn{2}{|c|}{ Sexo } & \multirow{2}{*}{ Total } \\
\hline & Masculino & Feminino & \\
\hline \multirow{2}{*}{ Até 1976} & 8 & 16 & 24 \\
\hline & 33,3 & 66,7 & $100 \%$ \\
\hline \multirow{2}{*}{ Após 1976} & 33 & 23 & 56 \\
\hline & 58,9 & 41,1 & $100 \%$ \\
\hline \multirow{2}{*}{ Total } & 41 & 39 & 80 \\
\hline & 51,3 & 48,8 & $100 \%$ \\
\hline
\end{tabular}

Fonte: Mapeamento dos terreiros de Salvador. Ceao/Semur/ Sehab, 2008.

\section{Escolaridade, registro e documentação}

A maioria desses terreiros está registrada em alguma associação, Fenacab ou Acbantu, seguindo uma tendência de todo o universo dos terreiros pesquisados (Tabela 6). E quanto maior o grau de escolaridade, maior a parcela dos registrados nas entidades afro-religiosas.

Tanto os terreiros liderados por homens quanto os liderados por mulheres têm percentual de registro acima de 77,0\%. Enquanto entre os 
Tabela 6

Condição de registro

segundo a escolaridade da liderança religiosa

Salvador, 2006-2008

\begin{tabular}{|c|c|c|c|c|c|}
\hline \multirow{3}{*}{$\begin{array}{l}\text { Condição de } \\
\text { registro }\end{array}$} & \multicolumn{4}{|c|}{ Escolaridade } & \multirow{3}{*}{ Total } \\
\hline & \multicolumn{2}{|c|}{ Até o curso médio completo } & \multicolumn{2}{|c|}{ Superior incomp. e completo } & \\
\hline & Masculino & Feminino & Masculino & Feminino & \\
\hline \multirow{2}{*}{ Registrado } & 291 & 555 & 34 & 34 & 914 \\
\hline & 78,0 & 81,3 & 82,9 & 91,9 & 80,6 \\
\hline \multirow{2}{*}{ Não registrado } & 82 & 128 & 7 & 3 & 220 \\
\hline & 22,0 & 18,7 & 17,1 & 8,1 & 19,4 \\
\hline \multirow{2}{*}{ Total } & 373 & 683 & 41 & 37 & 1134 \\
\hline & $100 \%$ & $100 \%$ & $100 \%$ & $100 \%$ & $100 \%$ \\
\hline
\end{tabular}

Fonte: Mapeamento dos terreiros de Salvador. Ceao/Semur/ Sehab, 2008.

Tabela 7

Constituição como associação, segundo a escolaridade da liderança religiosa Salvador, 2006-2008

\begin{tabular}{lccc}
\hline Constituição como & \multicolumn{2}{c}{ Escolaridade } & \\
\cline { 2 - 3 } associação civil & $\begin{array}{c}\text { Até o curso médio } \\
\text { completo }\end{array}$ & $\begin{array}{c}\text { Superior incomp. e } \\
\text { completo }\end{array}$ & Total \\
\hline $\begin{array}{l}\text { Constituído como } \\
\text { associação civil }\end{array}$ & 77 & 16 & 93 \\
Não é associação civil & 7,4 & 20,0 & 8,3 \\
& 969 & 64 & 1033 \\
Total & 92,6 & 80,0 & 91,7 \\
& 1046 & 80 & 1126 \\
\hline
\end{tabular}

Fonte: Mapeamento dos terreiros de Salvador. Ceao/Semur/ Sehab, 2008.

que haviam cursado até o ensino médio completo a diferença na parcela de terreiros registrados era de 3,3 pontos percentuais em favor dos liderados pelas mulheres, havia uma maior distância para os que tinham curso superior incompleto e completo, pois essa distância alçava a 9,0 pontos percentuais.

Em relação à constituição do terreiro como associação civil, encontramos diferenças significativas relacionadas com a escolaridade da liderança religiosa (Tabela 7). É quase o triplo a diferença entre os dois 
Tabela 8

Documentação dos imóveis, segundo a escolaridade da liderança religiosaa Salvador, 2006-2008

\begin{tabular}{|c|c|c|c|c|}
\hline \multirow[b]{2}{*}{ Documentação do imóvel } & \multicolumn{2}{|c|}{ Escolaridade } & \multirow{2}{*}{\multicolumn{2}{|c|}{ Total }} \\
\hline & $\begin{array}{l}\text { Até o curso médio } \\
\text { completo }\end{array}$ & $\begin{array}{l}\text { Superior incomp. e } \\
\text { completo }\end{array}$ & & \\
\hline \multirow{2}{*}{ Sem documentação } & 214 & 15 & 229 & \\
\hline & 20,9 & 19,5 & & 20,8 \\
\hline \multirow{2}{*}{ Escritura registrada } & 439 & 34 & 473 & \\
\hline & 42,8 & 44,2 & & 42,9 \\
\hline \multirow{2}{*}{ Escritura de doação } & 7 & & 7 & \\
\hline & 0,7 & & & 0,6 \\
\hline \multirow{2}{*}{ Registrada } & 14 & 2 & 16 & \\
\hline & 1,4 & 2,6 & & 1,5 \\
\hline \multirow{2}{*}{ Permissão de uso } & 10 & & 10 & \\
\hline & 1,0 & & & 1,0 \\
\hline \multirow{2}{*}{ Venda } & 265 & 23 & 288 & \\
\hline & 25,8 & 30,0 & & 26,1 \\
\hline \multirow{2}{*}{ Recibo } & 43 & 2 & 45 & \\
\hline & 4,2 & 2,6 & & 4,10 \\
\hline \multirow{2}{*}{ Outra documentação } & 34 & 1 & 35 & \\
\hline & 3,3 & 1,3 & & 3,2 \\
\hline \multirow{2}{*}{ Total } & 1026 & 77 & 1103 & \\
\hline & $100 \%$ & $100 \%$ & & $100 \%$ \\
\hline
\end{tabular}

Fonte: Mapeamento dos terreiros de Salvador. Ceao/Semur/ Sehab, 2008.

grupos. Um quinto dos terreiros liderados por pessoas com curso superior incompleto ou completo possuíam registro como associação civil, enquanto os de escolaridade até o ensino médio completo estavam representados em 7,4\%.

De todo modo, é muito alto o percentual dos que ingressaram no ensino superior, mas que não registraram o terreiro como associação civil: $80 \%$. Isto indicaria uma tendência das lideranças de qualquer ní- 
Tabela 9

Local de residência da liderança religiosa, segundo a sua escolaridade

Salvador, 2006-2008

\begin{tabular}{|c|c|c|c|c|}
\hline \multirow[t]{2}{*}{ Ano de fundação } & \multirow[t]{2}{*}{ Escolaridade } & \multicolumn{2}{|c|}{$\begin{array}{c}\text { Residencia na área do } \\
\text { terrreiro }\end{array}$} & \multirow[t]{2}{*}{ Total } \\
\hline & & Sim & Não & \\
\hline \multirow[t]{6}{*}{ Até 1976} & Até o curso médio & 307 & 49 & 356 \\
\hline & completo & 86,2 & 13,8 & $100 \%$ \\
\hline & Superior incompleto e & 17 & 7 & 24 \\
\hline & completo & 70,8 & 29,2 & $100 \%$ \\
\hline & \multirow{2}{*}{ Total } & 324 & 56 & 380 \\
\hline & & 85,3 & 14,7 & $100 \%$ \\
\hline \multirow[t]{6}{*}{ Após 1976} & \multirow{2}{*}{$\begin{array}{l}\text { Até o curso médio } \\
\text { completo }\end{array}$} & 576 & 107 & 683 \\
\hline & & 84,3 & 15,7 & $100 \%$ \\
\hline & \multirow{2}{*}{$\begin{array}{l}\text { Superior incompleto e } \\
\text { completo }\end{array}$} & 30 & 26 & 56 \\
\hline & & 53,4 & 46,4 & $100 \%$ \\
\hline & \multirow{2}{*}{ Total } & 606 & 133 & 739 \\
\hline & & 82,0 & 18,0 & $100 \%$ \\
\hline \multirow[t]{6}{*}{ Total } & Até o curso médio & 883 & 156 & 1039 \\
\hline & completo & 85,0 & 15,0 & $100 \%$ \\
\hline & \multirow{2}{*}{$\begin{array}{l}\text { Superior incompleto e } \\
\text { completo }\end{array}$} & 47 & 33 & 80 \\
\hline & & 58,8 & 41,3 & $100 \%$ \\
\hline & \multirow{2}{*}{ Total } & 930 & 189 & 1119 \\
\hline & & 83,1 & 16,9 & $100 \%$ \\
\hline
\end{tabular}

Fonte: Mapeamento dos terreiros de Salvador. Ceao/Semur/ Sehab, 2008.

vel de escolaridade a fazer o registro prioritariamente nas entidades afroreligiosas do que no âmbito jurídico-legal.

Em termos de documentação dos imóveis, a diferença é pequena entre os dois grupos de escolaridade (Tabela 8). E tanto entre os que não tinham documentação, quanto os que possuíam escritura registrada, não registrada e escritura de doação, a distância não alcançava dois pontos 
percentuais. As diferenças ultrapassam esse percentual somente para aqueles terreiros que possuíam recibo ou contrato de compra e venda.

\section{Escolaridade e local de residência}

A esmagadora maioria das lideranças religiosas reside na própria área do terreiro. De fato, para mais de dois quintos delas o espaço privado e o religioso é o mesmo. Contudo, entre pais e mães de santo com instrução equivalente ao curso superior completo ou incompleto essa maioria é bastante reduzida: $41,3 \%$ desse grupo declararam residir fora da área do terreiro (Tabela 9).

Os dados da pesquisa também sugerem que a tendência a residir fora do espaço religioso é mais intensa nos terreiros mais recentes. 18,0\% das lideranças religiosas dos terreiros criados após 1976 residem fora do terreiro em face de $14,7 \%$ dos lideres de instituições mais antigas na mesma condição. Essa parcela alcança 46,4\% entre os que tiveram acesso ao curso superior e pertencem a instituições criadas após 1976, em relação a $29,2 \%$ que têm a mesma escolaridade e estão em terreiros fundados antes de 1976.

\section{Escolaridade e ocupação}

O Mapeamento dos terreiros de Salvador revela que as lideranças religiosas com graus de instrução mais elevados, os "pais de santo doutores", têm presença mais intensa no mercado de trabalho. Metade do contingente com o curso superior completo ou incompleto acumulava, no momento da entrevista, o exercício de outra atividade com as tarefas relacionadas a sua função religiosa e quase a totalidade deles $(98,8 \%)$, em algum momento da vida, trabalhou. Entre as lideranças com menos escolaridade, essas porcentagens eram de $33,8 \%$ e $86,8 \%$, respectivamente. Replicando essas informações, os dados da pesquisa mostram que a parcela daqueles que possuem até o curso médio completo, e que jamais trabalhou (13,2\% deles), é cerca de dez vezes maior do que a dos que ingressaram nos cursos superiores $(1,3 \%)$ e encontram-se na mesma condição (Tabela 10$)$.

A exemplo do que acontece no mundo do trabalho soteropolita- 
Tabela 10

Ocorrência de trabalho das lideranças religiosas, segundo a escolaridade Salvador, 2006-2008

\begin{tabular}{|c|c|c|c|}
\hline \multirow[b]{2}{*}{ Ocorrência de trabalho } & \multicolumn{2}{|c|}{ Escolaridade } & \multirow[b]{2}{*}{ Total } \\
\hline & $\begin{array}{l}\text { Até o curso médio } \\
\text { completo }\end{array}$ & $\begin{array}{c}\text { Superior incomp. e } \\
\text { completo }\end{array}$ & \\
\hline \multirow{2}{*}{ Sim, tem outro trabalho } & 346 & 40 & 386 \\
\hline & 33,8 & 50,0 & 34,9 \\
\hline \multirow{2}{*}{ Sim, já teve outro trabalho } & 544 & 39 & 583 \\
\hline & 53,1 & 48,8 & 52,8 \\
\hline \multirow{2}{*}{ Nunca teve outra atividade } & 135 & 1 & 136 \\
\hline & 13,2 & 1,3 & 12,3 \\
\hline \multirow{2}{*}{ Total } & 1.025 & 80 & 1.105 \\
\hline & $100 \%$ & $100 \%$ & $100 \%$ \\
\hline
\end{tabular}

Fonte: Mapeamento dos terreiros de Salvador. Ceao/Semur/ Sehab, 2008.

no, os homens e os negros ${ }^{13}$ estão mais pressionados a buscar ocupação: $87,8 \%$ dos homens e $88,3 \%$ dos negros possuem ou possuíram trabalho, $85,7 \%$ das mulheres e $79,6 \%$ dos brancos. Esse quadro se mantém para os que possuem menos instrução, porém não se repete em relação às lideranças religiosas que ingressaram no curso superior. Nesse grupo, a totalidade das mulheres e também a dos brancos têm ou tiveram trabalho, em relação a 97,6\% dos homens e $98,5 \%$ dos negros.

A escolaridade parece diferenciar também as lideranças religiosas em relação à busca por uma ocupação no mercado de trabalho, que é mais intensa entre os universitários. Questionados sobre isso, 11,6\% dos que haviam ingressado nas faculdades responderam que tomaram alguma iniciativa para encontrar trabalho nos sete dias anteriores à entrevista, contra apenas $8,0 \%$ dos que tinham até o nível médio completo. No outro extremo, observa-se que enquanto $45,3 \%$ dos pais e mães de santo com até o curso médio completo jamais haviam pressionado o

13 Além desses grupos, todas as oito lideranças que se declararam amarelas, e 28 em 31 indígenas estavam ou estiveram envolvidas em situações de trabalho. 
mercado de trabalho em busca de uma ocupação, apenas $36,2 \%$ dos que possuíam mais instrução não o fizeram (Tabela 11).

Tabela 11

Última procura por trabalho das lideranças religiosas

Salvador, 2006-2008

\begin{tabular}{|c|c|c|c|}
\hline \multirow[b]{2}{*}{ Última procura por trabalho } & \multicolumn{2}{|c|}{ Escolaridade } & \multirow[b]{2}{*}{ Total } \\
\hline & $\begin{array}{l}\text { Até o curso médio } \\
\text { completo }\end{array}$ & $\begin{array}{c}\text { Superior incomp. e } \\
\text { completo }\end{array}$ & \\
\hline \multirow[b]{2}{*}{ Nos últimos 7 dias } & 80 & 8 & 88 \\
\hline & 8,0 & 11,6 & 8,2 \\
\hline \multirow[b]{2}{*}{ Nos últimos 30 dias } & 19 & & 19 \\
\hline & 1,9 & & 1,8 \\
\hline \multirow[b]{2}{*}{ No último ano } & 38 & 1 & 39 \\
\hline & 3,8 & 1,4 & 3,7 \\
\hline \multirow[b]{2}{*}{ Há mais de 1 ano } & 409 & 35 & 444 \\
\hline & 40,9 & 50,7 & 41,6 \\
\hline \multirow[b]{2}{*}{ Nunca procurou } & 453 & 25 & 478 \\
\hline & 45,3 & 36,2 & 44,8 \\
\hline \multirow[t]{2}{*}{ Total } & 999 & 69 & 1068 \\
\hline & $100 \%$ & $100 \%$ & $100 \%$ \\
\hline
\end{tabular}

Fonte: Mapeamento dos terreiros de Salvador. Ceao/Semur/ Sehab, 2008.

Rompida a barreira representada pelo acesso a uma ocupação em um mercado de trabalho, cujas taxas de desemprego são as mais elevadas entre todas as Regiões Metropolitanas brasileiras pesquisadas, ${ }^{14}$ às lideranças religiosas com mais escolaridade estão destinadas as posições ocupacionais mais estruturadas, ou seja, os postos de trabalho mais qualificados. É o que sugerem as informações contidas na Tabela 12.

Enquanto pouco mais da metade $(54,8 \%)$ das lideranças religiosas com até o nível médio completo encontra-se no trabalho assalaria-

\footnotetext{
${ }^{14}$ A taxa de desemprego total dessa região foi calculada em $23,6 \%, 21,7 \%$ e $20,3 \%$ nos anos 2006, 2007 e 2008 pela Pesquisa de Emprego e Desemprego da Região Metropolitana de Salvador. Esses resultados foram os mais elevados entre as seis regiões metropolitanas pesquisadas (Porto Alegre, São Paulo, Belo Horizonte, Brasília, Salvador e Recife).
} 
Tabela 12

Posições ocupacionais das lideranças religiosas, segundo a escolaridade

Salvador, 2006-2008

\begin{tabular}{|c|c|c|c|}
\hline \multirow[b]{2}{*}{ Posição na ocupação } & \multicolumn{2}{|c|}{ Escolaridade } & \multirow[b]{2}{*}{ Total } \\
\hline & $\begin{array}{l}\text { Até o curso médio } \\
\text { completo }\end{array}$ & $\begin{array}{c}\text { Superior incomp. e } \\
\text { completo }\end{array}$ & \\
\hline \multirow{2}{*}{ Assalariado } & 484 & 65 & 549 \\
\hline & 54,8 & 84,4 & 57,1 \\
\hline \multirow{2}{*}{$\begin{array}{l}\text { Assalariado do setor } \\
\text { privado }\end{array}$} & 296 & 21 & 317 \\
\hline & 33,5 & 27,3 & 33,0 \\
\hline \multirow{2}{*}{ Ass. privado c/carteira } & 257 & 20 & 277 \\
\hline & 29,1 & 26,0 & 28,8 \\
\hline \multirow{2}{*}{ Ass. privado s/carteira } & 39 & 1 & 40 \\
\hline & 4,4 & 1,3 & 4,2 \\
\hline \multirow{2}{*}{$\begin{array}{l}\text { Assalariado do setor } \\
\text { público }\end{array}$} & 112 & 36 & 148 \\
\hline & 12,7 & 46,8 & 15,4 \\
\hline \multirow{2}{*}{ Assalariado não sabe } & 76 & 8 & 84 \\
\hline & 8,6 & 10,4 & 7,8 \\
\hline \multirow{2}{*}{ Autônomo } & 352 & 10 & 362 \\
\hline & 39,8 & 13,0 & 37,7 \\
\hline \multirow{2}{*}{ Empregador } & 2 & & 2 \\
\hline & 0,2 & & 0,2 \\
\hline \multirow{2}{*}{ Empregado doméstico } & 38 & & 38 \\
\hline & 4,3 & & 4,0 \\
\hline \multirow{2}{*}{ Outra } & 8 & 2 & 10 \\
\hline & 0,9 & 2,6 & 1,0 \\
\hline \multirow{2}{*}{ Total } & 884 & 77 & 961 \\
\hline & $100 \%$ & $100 \%$ & $100 \%$ \\
\hline
\end{tabular}

Fonte: Mapeamento dos terreiros de Salvador. Ceao/Semur/ Sehab, 2008.

do, a parcela dos que ingressaram no curso superior nessa posição ocupacional chega a mais de quatro quintos $(84,4 \%)$ do conjunto. No trabalho assalariado, chama à atenção a forte diferença entre os grupos em relação ao acesso aos postos de trabalho do setor público, favoravelmente aos que ingressam no curso superior $(46,8 \%$ em relação a $12,7 \%$ ) e também maior presença dos menos escolarizados no setor privado (33,5\% e 27,3\%). Na situação de autônomo, reconhecidamente 
instável e precária em Salvador, encontram-se 13,0\% dos que ingressaram no curso superior e uma parcela três vezes maior $(39,8 \%)$ dos que possuem menos instrução.

Resumidamente, $47,1 \%$ das lideranças religiosas com até o curso médio e $14,3 \%$ daquelas que ingressaram no curso superior encontramse nas posições ocupacionais mais vulneráveis do trabalho assalariado sem carteira assinada no setor privado, no emprego doméstico, como autônomo, ou na categoria 'Outra', que inclui o trabalho familiar.

As tarefas que realizam durante o trabalho, ou aquilo que fazem, também diferenciam o espaço ocupacional dos líderes religiosos com até o segundo grau daquele destinado aos que possuem mais escolaridade. Perguntados sobre o que faziam ou realizavam no trabalho, 881 pessoas do primeiro grupo elencaram 177 ocupações e 79 pessoas do segundo grupo, 33. Em face da grande variedade de situações de trabalho mencionadas, especialmente pelos que possuem menos instrução, selecionamos as mais frequentes em ambos os grupos (Tabela 13).

O resultado das sete ocupações mais indicadas parece ser representativo. No caso dos menos escolarizados, elas respondem por quase metade das lideranças pesquisadas (416 pessoas ou 47,3\%) e, no caso dos mais instruídos, por quase dois terços (52 pessoas ou 65,8\%).

De um modo geral, as ocupações das lideranças religiosas com até o nível médio completo correspondem a posições subalternas e de pouco prestígio na área de serviços pessoais, de alimentação, domésticos ou de saúde, pouco exigentes de qualificações formais e frequentemente incluídos entre as muitas atividades informais de Salvador. Já as das mais escolarizadas, além das exigências de instrução e/ou de qualificação, expressam prestígio social, propriedade de algum capital e estão entre as profissões mais formalizadas e melhor remuneradas.

Dois outros fenômenos chamam a atenção: a importância do emprego no setor público entre as ocupações mais presentes em ambos os grupos - na quinta posição entre os que têm até o nível médio e na segunda entre os que ingressaram no curso superior - e as diferenças no tipo de ocupação que concentra o maior número de pessoas em cada categoria: as baianas de acarajé, entre os que têm até o nível médio, e $o(a) s$ professore(a)s, nos que ingressaram na universidade. 
Tabela 13

Principais ocupações das lideranças religiosas segundo a escolaridade Salvador, 2006-2008

\begin{tabular}{lccc}
\hline \multirow{2}{*}{ Ocupações } & \multicolumn{3}{c}{ Até o curso médio completo } \\
\cline { 2 - 4 } & $\begin{array}{c}\text { Número de } \\
\text { lideranças }\end{array}$ & $\begin{array}{c}\text { Distribuição } \\
\text { relativa }\end{array}$ & $\begin{array}{c}\text { Distribuição } \\
\text { acumulada }\end{array}$ \\
\hline Baiana de acarajé & 83 & 9,4 & \\
Costureiro(a) & 78 & 8,9 & 18,3 \\
Cozinheiro(a) & 62 & 7,0 & 25,3 \\
Técnico(a) em enfermagem & 61 & 6,9 & 32,3 \\
Funcionário(a) público(a) & 48 & 5,5 & 37,7 \\
Empregada doméstica & 45 & 5,1 & 42,8 \\
Vendedor(a) & 39 & 4,4 & 47,3 \\
Total & 416 & 47,3 & \\
\hline & & Superior Incompleto e Completo \\
\hline Professor(a) & 27 & 34,2 & 41,8 \\
Funcionário(a) público(a) & 6 & 7,6 & 49,4 \\
Enfermeiro(a) & 6 & 7,6 & 54,4 \\
Técnico(a) em enfermagem & 4 & 5,1 & 59,5 \\
Comerciário(a) & 4 & 5,1 & 63,3 \\
Comerciante & 3 & 3,8 & 65,8 \\
Médico(a) & 2 & 65,8 & \\
Total & 52 & & \\
\hline
\end{tabular}

Fonte: Mapeamento dos terreiros de Salvador. Ceao/Semur/ Sehab, 2008.

No caso do funcionalismo público, deve-se considerar que esse segmento inclui uma diversidade grande de atividades e tarefas muito diferenciadas em relação ao prestígio social, rendimento e requerimento de instrução e/ou qualificação.

Em relação à ocupação mais comum, entre os que foram agrupados em "até o ensino médio completo", observa-se com maior frequência a baiana de acarajé. São 83 lideranças, algumas delas "baianos de acarajé". Se comparado este número com o oficial ou estimado dessa profissão há uma sub-representação dessas lideranças vendendo o famoso bolinho. De acordo com a Associação das Baianas de Acarajé, Mingau e Receptivo (ABAM), o número oficial de vendedoras de acarajé 
saiu de 166 (1977) para 2,7 mil em 2007. A estimativa da Associação é que haja mais de cinco mil vendedoras. ${ }^{15}$

Entretanto, a presença do povo de santo é majoritária, à medida que se identifica a participação de filhas de santo, assim como a de outras funções hierárquicas nos tabuleiros da cidade. O que demonstra uma vinculação direta com um dos símbolos por excelência da herança de matriz africana, revelando que os processos de elaboração e distribuição de acarajés são etnicamente marcados no universo afro-religioso. Não é à toa que o povo de santo tem reagido à entrada em cena, na última década, de vendedoras de acarajé adeptas de igrejas neopentencostais. Isto é visto pelos candomblecistas como um ultraje à tradição afro-baiana, já que o acarajé é identificado como um alimento votivo do orixá Iansã. A apropriação por evangélicos é publicizada por estes como "o acarajé do Senhor ou de Jesus", retirando, portanto, qualquer significado de associação com mitos e símbolos da religiosidade afro-baiana. Infelizmente, ainda não há dados sobre esses vendedores de acarajé neopentencostais para que pudéssemos comparar a sua representação nesse mercado. ${ }^{16}$

\section{Considerações finais}

Como vimos, não é novidade a presença de lideranças brancas em terreiros baianos. Trata-se de algo verificado há mais de um século. Essa visibilidade já foi alvo de reflexão em contextos distintos (paulistano e gaúcho). Esses dois exemplos revelam tensões explícitas e implícitas em terreiros liderados por brancas ou negras. ${ }^{17}$

E a temática sobre embranquecimento já aparecia, mesmo que tangencialmente, no final dos anos trinta. Donald Pierson argumentava que as lideranças masculinas dos candomblés baianos, ao contrário das femini-

\footnotetext{
15 Florismar M. Borges, "Acarajé - tradição e modernidade” (Dissertação de Mestrado, Universidade Federal da Bahia, 2008).

16 Sobre o acarajé na simbologia afro-religiosa, ver Vivaldo da Costa Lima, "As dietas africanas no sistema alimentar brasileiro", in C. Cardoso, e J. Bacelar (orgs.), Faces da tradição afrobrasileira: religiosidade, sincretismo, anti-sincretismo, reafricanização (Rio de Janeiro/ Salvador: Pallas, 1999), pp. 319-26.

17 Vagner G. da Silva e Rita de Cássia Amaral, "A cor do axé. Brancos e negros no candomblé de São Paulo", Estudos Afro-Asiáticos, n. 25 (1993), pp. 99-124; Pedro A. Oro, "As relações raciais nos terreiros do Rio Grande do Sul”, Estudos Afro-Asiáticos, n. 33 (1998), pp. 31-50.
} 
nas, não passavam por um rigoroso processo de iniciação e, desse modo, por serem "mais móveis" que as mães de santo, tinham um maior contato com indivíduos de "cultura europeia"; por conseguinte, tendiam a se "apropriar com mais facilidade das ideias e sentimentos dos brancos". ${ }^{18}$ Presumimos que se tratasse de indivíduos mestiços ou pretos.

Se essa hipótese denotava a perspectiva de um maior rigor da tradição vinculada exclusivamente ao universo feminino, algo que também sobressai no trabalho de Ruth Landes, ${ }^{19}$ a dinâmica das relações raciais e de gênero presentes nos terreiros nas últimas três décadas aponta para uma mudança nas seguintes direções: o crescimento de lideranças masculinas - entre os terreiros fundados até 1976, a parcela masculina era de $27,3 \%$ e entre os criados posteriormente, $41,8 \%$; o aumento de terreiros liderados por brancos era $15(3,9 \%)$ na metade da década de setenta e em 2008 passou a ser 53 (4,8\%); e o aumento que consideramos substantivo das lideranças que ingressaram no ensino superior eram 24 (até 1976) e passaram a 56 no período posterior. E, como demonstramos, a escolaridade é uma variável significativa para se avaliar, por exemplo, a relação da cor das lideranças com a sua inserção no mercado de trabalho ou mesmo o local de residência.

A esses dados devem ser acrescidos novos significados do que sejam os valores relacionados à negritude. Se não faz mais sentido apontar a absorção de um "embranquecimento" exclusivamente pelas lideranças masculinas, salta aos nossos olhos o discurso proferido por uma mãe de santo, autodeclarada "branca retinta" e com escolaridade superior completa. Ao defender as religiões afro-brasileiras dos ataques dos evangélicos afirmava categoricamente em um espaço público: "Nós, negros; nós, iorubas...". Por isso, quem irá negar a sua nova identidade, agora enegrecida, afinal de contas anteriormente ela era da nação umbandista.

Texto recebido em 19 de janeiro de 2013 e aprovado em 19 de abril de 2013.

18 Pierson, Brancos e pretos na Bahia, p. 312.
19 Landes, A cidade das mulheres. 


\title{
Resumo
}

O artigo examina algumas categorias como escolaridade, cor, gênero e ocupação em terreiros baianos, através de dados produzidos no mapeamento dos candomblés na cidade de Salvador. O mapeamento teve como objetivo realizar um censo desse universo buscando dados relativos às lideranças religiosas como cor, escolaridade, gênero e ocupação, assim como dados sobre os terreiros. Analisamos a dinâmica dos terreiros baianos e como isto pode ser vista em relação à presença de lideranças com educação superior, através de categorias como cor e gênero, principalmente com a entrada em cena de indivíduos que se autoclassificaram como brancos.

Palavras-chave: terreiros de candomblé - Salvador - cor - escolaridade - gênero

\begin{abstract}
This article examines some categories such as level of education, gender, race, and occupation in Afro-Bahian religions, through data produced by mapping of Candomble terreiros/temples in Salvador, Bahia, Brazil. The mapping had as an objective to carry out a census of this universe searching for data related to religious leaderships such as race, level of education, gender, and occupation, as well as other data on these terreiros. We analyze the dynamics of the AfroBahian terreiros and how this can be observed in relation to the presence of leaderships with higher education, through categories like race and gender, mainly with the entrance of leadership that classified themselves as white.
\end{abstract}

Keywords: Afro-Bahian temples-Salvador-race-level of education-gender. 